\title{
Identification of Coccoidal Bacteria in Traditional Fermented Milk Products from Mongolia, and the Fermentation Properties of the Predominant Species, Streptococcus thermophilus
}

\author{
Yan Ren, Wenjun Liu, and Heping Zhang* \\ Key Laboratory of Dairy Biotechnology and Engineering, Education Ministry of P. R. China, \\ Department of Food Science and Engineering, Inner Mongolia Agricultural University, Hohhot 010018, China
}

\begin{abstract}
The objective of this study was to identify the coccoidal bacteria present in 188 samples of fermented yaks', mares' and cows' milk products collected from 12 different regions in Mongolia. Furthermore, we evaluated the fermentation properties of ten selected isolates of the predominant species, Streptococcus $(S$.) thermophiles, during the process of milk fermentation and subsequent storage of the resulting yoghurt at $4^{\circ} \mathrm{C}$. Overall, 159 isolates were obtained from 188 samples using M17 agar. These isolates were presumed to be lactic acid bacteria based on their gram-positive and catalase-negative properties, and were identified to species level using 16S rRNA gene sequence analysis. These coccoid isolates were distributed in four genera and six species: Enterococcus (E.) durans, Enterococcus (E.) faecalis, Lactococcus (Lac.) subsp. lactis, Leuconostoc (Leuc.) lactis, Leuconostoc (Leuc.) mesenteroides. subsp. mesenteroides and $S$. thermophilus. Among these $S$. thermophilus was the most common species in most samples. From evaluation of the fermentation characteristics (viable counts, $\mathrm{pH}$, titratable acidity [TA]) of ten selected $S$. thermophilus isolates we could identify four isolates (IMAU 20246, IMAU20764, IMAU20729 and IMAU20738) that were fast acid producers. IMAU20246 produced the highest concentrations of lactic acid and formic acid. These isolates have potential as starter cultures for yoghurt production.
\end{abstract}

Keywords: coccoidal bacteria, fermentation properties, Streptococcus thermophilus, traditional fermented milk products

Received May 19, 2015; Revised September 25, 2015; Accepted September 26, 2015

\section{Introduction}

Fermentation is one of the oldest technologies for processing and preserving food in Mongolia (Liu et al., 2011). Spontaneous fermentation of milk into various different products for local consumption has a long history and cultures of the beneficial microorganisms that facilitate this fermentation, are handed down from one generation to the next (Yu et al., 2011); many naturally fermented milk products are produced traditionally without any commercial starter cultures. There is a wide bacterial biodiversity associated with each dairy product but by far the most common bacteria in fermented foods are lactic acid bacteria (LAB) (Chao et al., 2009; Lu et al., 2008). $\mathrm{LAB}$ are increasingly finding acceptance as probiotics that stimulate the host's immune system, lower the risk of

\footnotetext{
*Corresponding author: Heping Zhang, Key Laboratory of Dairy Biotechnology and Engineering, Ministry Education of China, Hohhot 010018, China. Tel: +86-0471-4319940, Fax: +86-04714305357, E-mail: hepingdd@vip.sina.com
}

cancer and prevent infection by pathogenic microorganisms (Castellano et al., 2010; Mohd Adnan and Tan, 2010).

The objective of the present study was to isolate and identify the coccoidal bacteria from traditionally fermented milk products from Mongolia, and quantify the acidification properties of Streptococcus (S.) thermophilus during milk fermentation and subsequent storage. This study focus on coccoidal bacteria in order to screen optimal $S$. thermophius strains as starter culture. Due to $S$. thermophilus can produce lactic acid, fomic acid, extracellular polysaccharides and acetaldehyde, diacetyl and other flavoring substances, S. thermophilus is considered one of the important starter culture in dairy industry. It is often co-incultured with Lactobacillus (L.) delbrueckii subsp. bulgaricus to produce fermented milk and cheese. It is also alone or mixed with some Lactobacillus species to product Mozzarella and Cheddar cheese (Yu, 2014). Meanwhile, the rapid production of lactic acid during yoghurt manufacture is correlated with the quality and metabolic activity of the starter culture (Tabasco et al., 2014). Moreover variation in acidification activity of dif-

(9)This is an open access article distributed under the terms of the Creative Commons Attribution Non-Commercial License (http://creativecommons.org/licences/ by-nc/3.0) which permits unrestricted non-commercial use, distribution, and reproduction in any medium, provided the original wokr is properly cited. 
ferent isolates is related to their ability to assimilate the nutrients available in the growth medium (Badis et al., 2004). By evaluating the acidification ability of indigenous isolates of $S$. thermophilus from traditional fermented milk we aimed to select an optimal yoghurt starter culture (Soomro and Masud, 2008).

\section{Materials and Methods}

\section{Collection of samples}

The 188 samples of dairy products for evaluation were collected from 12 regions in Mongolia in 2009. The majority of samples were from products fermented using traditional processes. Samples were sealed in small, sterile tubes with $\mathrm{CaCO}_{3}$ and amylum (North Day Medical Reagent Company, China), placed on ice and rapidly returned to the laboratory for microbiological analysis.

\section{Enumeration of viable bacterial counts of coccoi- dal bacteria and their isolation}

Enumeration and isolation were performed following the methods of Yu et al (2011). $1 \mathrm{~mL}$ or $1 \mathrm{~g}$ of each product was mixed with $9 \mathrm{~mL}$ of $0.85 \%(\mathrm{w} / \mathrm{v})$ sterile physiological saline (North Day Medical Reagent Company, China). Serially diluted aliquots $\left(10^{1}-10^{8}\right)$ of milk samples were prepared in sterile physiological saline $(0.85 \%$ $\mathrm{NaCl})$. The dilutions $\left(10^{5}-10^{8}\right)$ were plated on appropriate M17 media (Oxoid Ltd., UK) which contain $0.01 \%$ (v/v) cycloheximide and polymyxin (North Day Medical Reagent Company, China) in duplicate.

Plates were incubated under anaerobic conditions at $30^{\circ} \mathrm{C}$ for $48 \mathrm{~h}$. Colonies with distinct morphological differences such as color, shape and size were selected by streaking at least three times on M17 agar (Oxoid Ltd., UK). Positive cocci isolates were indicated by a yellow clear zone around the colonies. These randomly selected colonies were tested for Gram stain, cell morphology, and catalase reaction before further identification. Distinctly Gram-positive, globular and catalase negative isolated colonies were purified and kept in M17 broth at $4^{\circ} \mathrm{C}$, and the frozen stock in $10 \%(\mathrm{w} / \mathrm{v})$ skim milk (Fonterra Ltd., New Zealand) broth were stored at $-80^{\circ} \mathrm{C}$. Lyophilization of isolates was performed for longer storage.

\section{S rRNA sequence identification}

All the strains grown in $5 \mathrm{~mL} \mathrm{M17}$ culture broth at $37^{\circ} \mathrm{C}$ were used for DNA extraction by a revised CTAB (cetyltrimethylammonium bromide) method. DNA from the $\mathrm{LAB}$ isolates was extracted following the methods of Chen et al. (2010). Purified DNA was diluted to $100 \mathrm{ng} / \mathrm{uL}$ of final concentration for 16S rRNA gene amplification. Approximately $1500 \mathrm{bp}$ of $16 \mathrm{~S}$ rRNA gene was amplified using a set of universal primers $27 \mathrm{~F}$ and $1495 \mathrm{R}$. The primer sequences were 27F, 5'-AGAGTTTGATCCTGGCTCAG-3', and 1495R, 5'-CTACGGCTACCTTGTTACGA3' (Wang et al., 2008). The 25 uL reaction mixture contained $100 \mathrm{ng}$ template DNA, $2.5 \mathrm{uL}$ 10× buffer (North Day Medical Reagent Company, China) with $1.5 \mathrm{mM} \mathrm{MgCl}_{2}$, 3.0 unit Taq DNA polymerase (TaKaRa Corporation, Dalian, China), $0.2 \mathrm{mM}$ of dNTP (TaKaRa), and $10 \mathrm{pmol}$ of each primer. The PCR amplifying procedure was as follows: $5 \mathrm{~min}$ at $94^{\circ} \mathrm{C}, 1 \mathrm{~min}$ at $72^{\circ} \mathrm{C}$ and then $10 \mathrm{~min}$ at $72^{\circ} \mathrm{C}$; It was carried out on an automatic thermal cycler (MJ Research PTC-200). PCR products were electrophoresed in $1.0 \%$ agarose gel and visualized by UV transillumination (UVP Company, USA) after ethidium bromide staining.

Positive PCR products were sent to Shanghai Sangni Biosciences Corporation of China for sequencing. Sequences were deposited in the GenBank database. Each sequence was used as a query sequence to search for similar sequences in GenBank using the BLAST software programme (Li et al., 2012).

\section{Fermentation and storage characteristics of selec- ted $S$. thermophiles isolates}

\section{Manufacture of fermented milk}

Whole milk powders (Fonterra Ltd., New Zealand) contained $39.1 \%$ lactose and $25.0 \%$ proteins (with a casein content above 34\%) (North Day Medical Reagent Company, China) were used in this study. The whole milk powders were used in this study. The whole milk powders were hydrated $(11.5 \%, \mathrm{w} / \mathrm{w})$ and supplemented with $6.5 \%$ sucrose (w/w) (Zha et al., 2015). The hydrated milks were heated to $85^{\circ} \mathrm{C}$ for $30 \mathrm{~min}$, cooled to $4^{\circ} \mathrm{C}$ and inoculated with the isolateds at an inoculation level of $5 \times 10^{6} \mathrm{CFU} / \mathrm{g}$. After inoculation, the milks were incubated at $37^{\circ} \mathrm{C}$. Samples were taken every two hours for the determination of the $\mathrm{pH}$ value, titratable acidity (TA), and viable count until the $\mathrm{pH}$ value reached 4.5.

Selection of $S$. thermophilus isolates for evaluation Ten isolates of $S$. thermophilus were selected from those that were isolated in section 2.2 for their rapid acidification characteristics and short fermentation times as observed in preliminary experiments. The selected isolates were IMAU20764, IMAU20765, IMAU20438, IMAU20728, IMAU20729, IMAU20246, IMAU20738, IMAU20796, 
Table 1. Phenotypic characteristics of 10 representative $S$. thermophilus strains from traditional fermented milk in Mongolia

\begin{tabular}{ccccc}
\hline \hline No. of isolates & Dairy product & Isolation location & Fermentation time & Fermentation $\mathrm{pH}$ \\
\hline IMAU20764 & Fermented cow milk & Wulaanbatar & $6 \mathrm{~h}$ & 4.48 \\
IMAU20765 & Fermented cow milk & Wulaanbatar & $5 \mathrm{~h}$ & 4.43 \\
IMAU20438 & Fermented cow milk & Hovsgol & $6 \mathrm{~h}$ & 4.48 \\
IMAU20728 & Fermented yak milk & Tov & $6 \mathrm{~h}$ & 4.42 \\
IMAU20729 & Fermented yak milk & Tov & $9 \mathrm{~h}$ & 4.5 \\
IMAU20246 & Fermented cow milk & Kentiy & $6.5 \mathrm{~h}$ & 4.57 \\
IMAU20738 & Fermented yak milk & Tov & $10 \mathrm{~h}$ & 4.49 \\
IMAU20796 & Fermented cow milk & Wulaanbatar & $10.3 \mathrm{~h}$ & 4.33 \\
IMAU20588 & Fermented cow milk & Arhangay & $10 \mathrm{~h}$ & 4.58 \\
IMAU20713 & Fermented yak milk & Tov & $11 \mathrm{~h}$ & 4.48 \\
\hline
\end{tabular}

h, hour.

IMAU20588 and IMAU20713. The detailed information of these ten $S$. thermophilus strains show in Table 1.

\section{Measurement of acidification characteristics during fermentation}

After inoculation, each sample was incubated at $37^{\circ} \mathrm{C}$. Every two hours samples were taken for evaluation of $\mathrm{pH}$, TA and viable bacterial counts until the $\mathrm{pH}$ value fell to 4.5 . The $\mathrm{pH}$ of samples was measured using a pHFE20 $\mathrm{pH}$ meter (Shanghai LTD, China). The TA was determined with $0.1 \mathrm{~N} \mathrm{NaOH}$ using $0.5 \%$ phenolphthalein (North Day Medical Reagent Company, China) as the indicator following the methods of Ali et al. (2015). The viable counts of $S$. thermophilus were enumerated on M17 agar according to the methods of Tharmaraj and Shah (2003).

Measurement of acidification characteristics during storage and post-fermentation ripening

Once the $\mathrm{pH}$ had fallen to 4.5 , that time was recorded, and the samples stored at $4^{\circ} \mathrm{C}$ for post-fermentation ripening. At $0 \mathrm{~h}$ and every $12 \mathrm{~h}$ thereafter for the $\mathrm{pH}$, TA and viable bacterial counts were measured as described in 2.4.2. Furthermore, at each of these time points $1 \mathrm{~g}$ samples were taken to determine the organic acid (lactic acid and formic acid) content (Chaves et al., 2002). Each $1 \mathrm{~g}$ sample was mixed with $3 \mathrm{~mL}, 1 \mathrm{M} \mathrm{HCl}$ in a $10 \mathrm{~mL}$ centrifuge tube and centrifuging at $4000 \mathrm{~g}$ for $10 \mathrm{~min}$; $1 \mathrm{~mL}$ samples of the supernatants were filtered through 0.45 $\mu \mathrm{m}$ membranes and stored at $-80^{\circ} \mathrm{C}$ prior to determining the concentration of lactic acid and formic acid using high performance liquid chromatography (HPLC) (Agilent Technologies Inc., USA) following the methods of Bruno et al (2002).

\section{Statistical analysis}

Statistical analysis of data was carried out using the software package SPSS. Differences between the means of the treatments were compared using ANOVA at the significance level of $p<0.05$.

\section{Results and Discussion}

\section{Enumeration of viable coccoidal bacteria counts}

The majority of isolates were presumed to be LAB based on characteristics such as gram-positive reactions and absence of catalase. In total, 250 presumptive LAB were isolated from 188 fermented milk samples. There are 159 coccoidal bacteria and 91 rod-shaped bacteria from M17 medium. More coccoidal bacteria were obtained from M17 media (63.6\%) than rod-shaped bacteria isolated from M17 media (36.4\%). Similar to our results, a prior study of LAB in yogurt demonstrated MRS as the medium of choice for differential counting of lactobacilli and M17 as the prefered medium for counting coccoidal bacteria (Coeuret et al., 2003). For our study we focused on coccoidal bacteria; the counts of viable cocci found in each sample, and the sampling locations are shown in Table 2. The average number of viable cocci from the milk products sampled and plated on to M17 agar varied from $8.80 \times 10^{6}$ to $3.47 \times 10^{8} \mathrm{CFU} / \mathrm{mL}$; the lowest average viable counts occurred in products from Kentiy. The average number of viable counts in Ovorhangay, Wulaanbatar and Tov varied widely in the range from $1.8 \times 10^{8}$ to $3.47 \times$ $10^{8} \mathrm{CFU} / \mathrm{mL}$. The variable ripening periods of the different products sampled, differences in transportation methods and different sampling regions may have contributed to this variability in the number of viable counts detected in this study.

\section{S rRNA sequence identification}

From their 16S rRNA gene sequences isolates could be divided into six species: Enterococcus (E.) faecalis, E. 
Table 2. Source location (province and dairy product) of samples and enumeration of viable counts of coccoid bacteria isolated from them onto M17 agar

\begin{tabular}{|c|c|c|c|c|c|}
\hline Province & $\begin{array}{c}\text { Counts of cocci } \\
(\mathrm{CFU} / \mathrm{mL})\end{array}$ & Dairy product & Species of coccoid isolates & $\begin{array}{l}\text { Number of } \\
\text { isolates }\end{array}$ & $\begin{array}{c}\text { Most prevalent } \\
\text { species }(\%)\end{array}$ \\
\hline \multirow{3}{*}{ Arhangay } & \multirow{3}{*}{$3.23 \times 10^{7}$} & \multirow{3}{*}{$\begin{array}{l}\text { Fermented } \\
\text { yaks' milk }\end{array}$} & S. thermophilus & 13 & \multirow{3}{*}{ S. thermophiles (76\%) } \\
\hline & & & Leuc. lactis & 2 & \\
\hline & & & Leuc. mesenteroides. subsp. mesenteroides & 2 & \\
\hline \multirow{2}{*}{ Bulgan } & \multirow{2}{*}{$2.73 \times 10^{7}$} & \multirow{2}{*}{$\begin{array}{l}\text { Fermented } \\
\text { cows' milk }\end{array}$} & S. thermophilus & 11 & \multirow{2}{*}{ S. thermophiles (92\%) } \\
\hline & & & Leuc. lactis & 1 & \\
\hline \multirow{3}{*}{ Dornod } & \multirow{2}{*}{$1.50 \times 10^{7}$} & \multirow{2}{*}{$\begin{array}{l}\text { Fermented } \\
\text { cows' milk }\end{array}$} & S. thermophilus & 3 & \multirow{2}{*}{ S. thermophiles $(75 \%)$} \\
\hline & & & Leuc. lactis & 1 & \\
\hline & \multirow{5}{*}{$1.05 \times 10^{7}$} & \multirow{5}{*}{$\begin{array}{l}\text { Fermented } \\
\text { cows' milk }\end{array}$} & S. thermophilus & 17 & \multirow{5}{*}{ S. thermophilus (81\%) } \\
\hline \multirow{4}{*}{ Dzavhan } & & & Lac. lactis subsp. lactis & 1 & \\
\hline & & & Leuc. lactis & 1 & \\
\hline & & & Leuc. mesenteroides. subsp. mesenteroides & 1 & \\
\hline & & & E. durans & 1 & \\
\hline \multirow{3}{*}{ Hovsgol } & \multirow{3}{*}{$1.53 \times 10^{7}$} & \multirow{3}{*}{$\begin{array}{l}\text { Fermented } \\
\text { cows' milk }\end{array}$} & S. thermophiles & 22 & \multirow{2}{*}{ S. thermophilus (92\%) } \\
\hline & & & Leuc. mesenteroides subsp.mesenteroides & 2 & \\
\hline & & & S. thermophiles & 7 & \multirow{4}{*}{ S. thermophilus (70\%) } \\
\hline \multirow{3}{*}{ Kentiy } & \multirow{3}{*}{$8.80 \times 10^{6}$} & \multirow{3}{*}{$\begin{array}{l}\text { Fermented } \\
\text { cows' milk }\end{array}$} & Leuc. lactis & 1 & \\
\hline & & & E. faecalis & 1 & \\
\hline & & & E. durans & 1 & \\
\hline \multirow{2}{*}{ Orhan } & \multirow{2}{*}{$1.57 \times 10^{7}$} & \multirow{2}{*}{$\begin{array}{l}\text { Fermented } \\
\text { cows' milk }\end{array}$} & S. thermophiles & 12 & \multirow{2}{*}{ S. thermophilus (86\%) } \\
\hline & & & Leuc. mesenteroides. subsp. mesenteroides & 2 & \\
\hline \multirow{4}{*}{ Ovorhangay } & \multirow{4}{*}{$1.52 \times 10^{8}$} & & Leuc. mesenteroides. subsp. mesenteroides & 3 & \\
\hline & & Fermented & Leuc. lactis & 2 & Leuc. mesenteroides \\
\hline & & cows' milk & E. durans & 1 & $\begin{array}{l}\text { suosp. mesenterolaes } \\
(43 \%)\end{array}$ \\
\hline & & & Lac. lactis subsp. lactis & 1 & \\
\hline Selenge & $231 \times 10^{7}$ & Fermented & S. thermophilus & 1 & Leuc lactis $(67 \%)$ \\
\hline & & mares' milk & Leuc. lactis & 2 & Leuc. lactls (6/\%) \\
\hline Suhbaater & $9.66 \times 10^{6}$ & Fermented & S. thermophiles & 9 & $S$ thermonhilus (64\%) \\
\hline & & cows' milk & Lac. lactis subsp. lactis & 5 & \\
\hline Tov & $1.80 \times 10^{8}$ & $\begin{array}{l}\text { Fermented } \\
\text { cows' milk }\end{array}$ & S. thermophilus & 15 & S. thermophilus $(100 \%)$ \\
\hline & & & S. thermophilus & 14 & \\
\hline Wulaanbatar & $3.47 \times 10^{8}$ & Fermented & Lac. lactis subsp. lactis & 1 & S. thermophilus (78\%) \\
\hline & & & Leuc. mesenteroides subsp. mesenteroides & 3 & \\
\hline
\end{tabular}

S. thermophilus, Streptococcus thermophilus; Leuc. lactis, Leuconostoc lactis; Leuc. mesenteroides. subsp. mesenteroides, Leuconostoc mesenteroides. subsp. mesenteroides; Lac. lactis subsp. lactis, Lactococcus lactis subsp. lactis; E. durans, Enterococcus durans; E. faecalis, Enterococcus faecalis.

durans, Lactococcus (Lac.) lactis subsp. lactis, Leuconostoc (Leuc.) mesenteroides subsp. mesenteroides, Leuc. lactis, S. thermophilus (Table 2). The predominant species was $S$. thermophilus, which was isolated from all sampling sites and represented $29.3 \%$ of all isolates collected. Previous studies have shown similar results; $S$. thermophilus was the most frequently isolated bacteria from Columbian dairy products, representing $41.2 \%$ of all isolates collected, which was higher than in our study (Vélez et al., 2007).

The predominant species present varied depending on the fermented milk product from which it was isolated and the region of Mongolia. For example, 76\% (13/17) of isolates from fermented yaks' milk products from Arhangay were $S$. thermophilus. $92 \%$ (11/12) of isolates from fermented cow milk products from Bulgan were $S$. thermophilus. $75 \%$ (3/4) of isolates from fermented cow milk products from Dornod were S. thermophilus. 81\% (17/21) of isolates from fermented cow milk products from Dzavhan were $S$. thermophilus. $92 \%$ (22/24) of isolates from fermented cow milk products from Hovsgol were $S$. thermophilus. $70 \%$ (7/10) of isolates from fermented cow milk from Kentiy were $S$. thermophilus. 86\% (12/14) of isolates from fermented cow milk products from Orhan were $S$. thermophilus. 43\% (3/7) of isolates from fermented cow milk from Ovorhangay were Leuc. mesenteroides 
subsp. mesenteroides. $67 \%(2 / 3)$ of isolates from fermented mare milk products from selenge were Leuc. lactis. $64 \%(9 / 14)$ of isolates from fermented cow milk products from Suhbaater were $S$. thermophilus. $100 \%(15 / 15)$ of isolates from fermented cow milk from Tov were $S$. thermophilus. 78\% (14/18) of isolates from fermented cow milk products from Wulaanbatar were S. thermophilus.

The diversity of species present appears to vary by region and the fermented milk product. This diversity is not surprising because many factors may influence the presence or absence of particular species. These include, different production methods, recipes and raw materials. Furthermore, the variability in environmental conditions at each location could also contribute to this variation, as has been observed in other studies (Yu et al., 2012).

Changes in $\mathrm{pH}$, TA and bacterial viability during fermentation of milk by ten $\boldsymbol{S}$. thermophilus isolates As expected, an increase in TA and a decrease in $\mathrm{pH}$ of milk, were observed in milk during fermentation by all isolates of $S$. thermophilus (Fig. 1). It took less than $10 \mathrm{~h}$ for milk to reach a $\mathrm{pH}$ of 4.5 when fermented by all $S$. thermophilus isolates, due to their rapid acidification capacity; amongst the $S$. thermophilus isolates, IMAU20765 acheived the fastest $\mathrm{pH}$ reduction (within $4 \mathrm{~h}$ ) and IMAU 20713 was the slowest $(10 \mathrm{~h}$ ). Two isolates (IMAU20765 and IMAU20246) would be good candidates for use as yoghurt starter cultures because they reduce the $\mathrm{pH}$ to approximately 4.5 within $6 \mathrm{~h}$, which is considered an optimal time from previous studies (Erkus et al., 2013). By the end of fermentation, three isolates (IMAU20246, IMAU20713 and IMAU20765) had the highest TA values of $59.03,57.72$ and $57.16^{\circ} \mathrm{T}$, respectively. The remaining seven isolates (IMAU20764, IMAU20438, IMAU 20728, IMAU20729, IMAU20738, IMAU20796 and IMAU20588) had a relatively lower acidification capacity. All ten isolates achieved TA values in excess of 50.00 ${ }^{\circ} \mathrm{T}$ within $10 \mathrm{~h}$ of initiating fermentation. This would
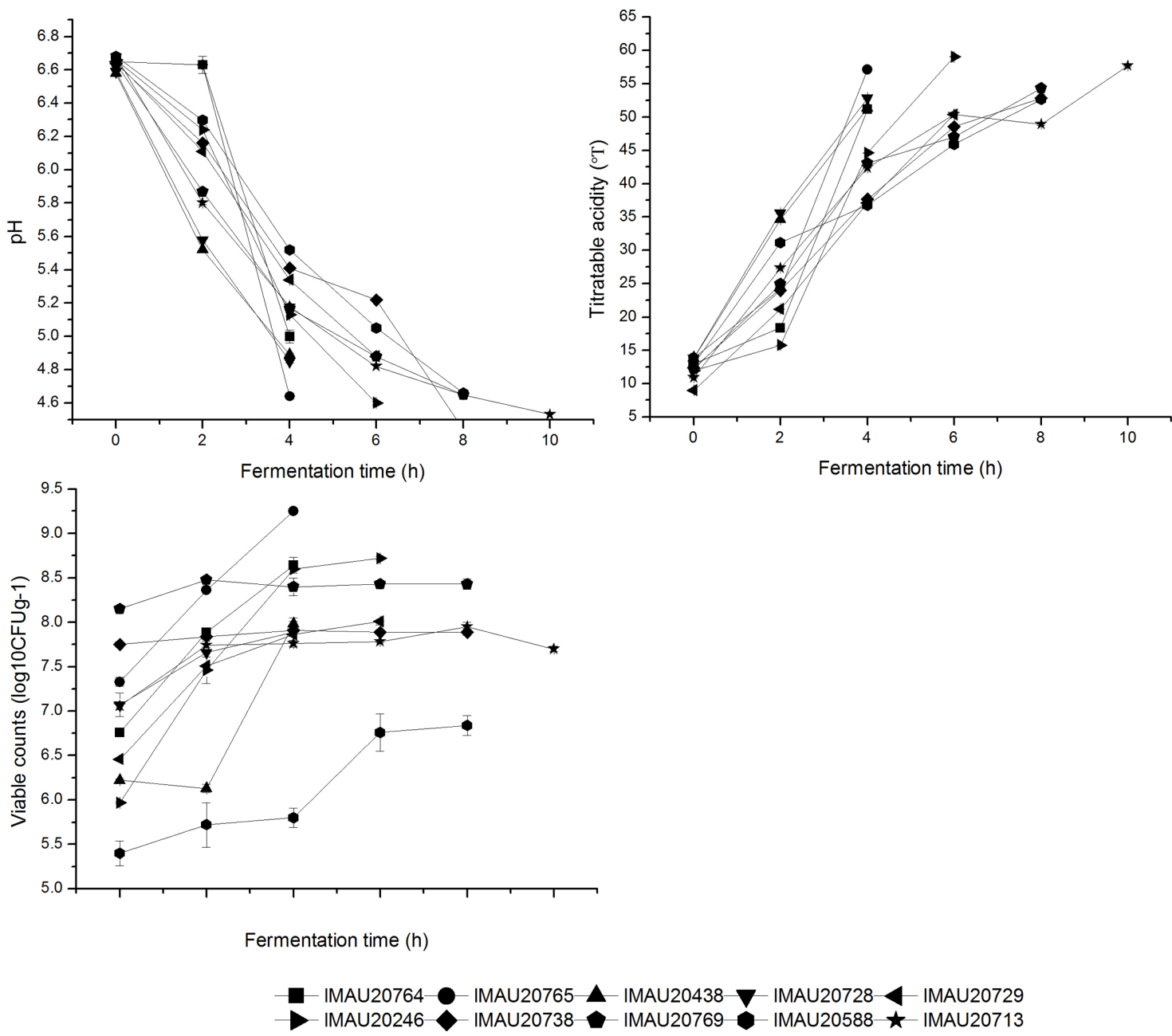

Fig. 1. Effect of fermentation time on $\mathrm{pH}$, TA and viable counts in milk inoculated with ten $S$. thermophiles isolates. 
allow them all to be considered as 'fast acid-producing isolates' for yoghurt production according to the catagories described by Raquib et al. (2003). Soomro and Masud (2008) found that the majority of isolates of S. thermophilus derived from dahi yoghurt were also fast acidifiers. In contrast, all S. thermophilus isolates from fermented milk laban had low acid-producing capabilities (Chammas et al., 2006), suggesting that $S$. thermophilus from different dairy products vary in their acidification capabilities.

Rapid growth of $S$. thermophilus in milk is a reflection of their high proteolytic activity (Letort and Juillard, 2001). Previously, cheese-derived $S$. thermophilus were thought to have the highest proteolytic activity (Donkor et al., 2006). However, in our study the final bacterial counts achieved in yoghurt production were greater than 6.84 $\log _{10} \mathrm{CFUg}^{-1}$, which is also high; IMAU20765 achieved the highest count of viable bacteria $\left(9.25 \log _{10} \mathrm{CFUg}^{-1}\right)$ (Fig. 1). Our results were similar to those reported by Güler-Akn and Akn (2007), confirming S. thermophilus as the predominant and most rapidly acidifying species among LAB.
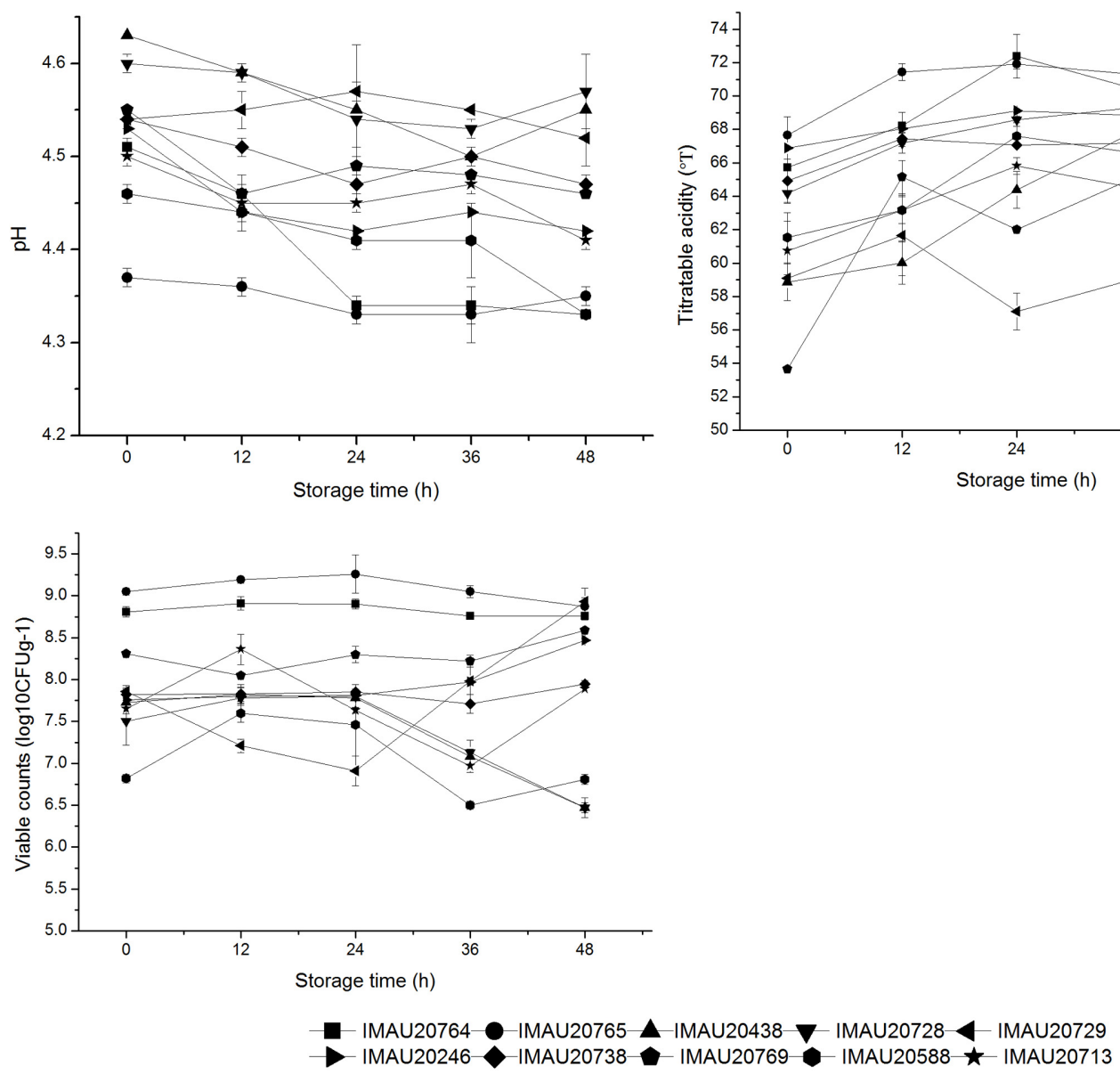

Fig. 2. Effect of storage time on $\mathrm{pH}$, TA and viable counts in yoghurt made using ten $S$. thermophilus isolates.

\section{Changes in $\mathrm{pH}, \mathrm{TA}$ and bacterial viability during storage of fermented milk produced by ten $S$. ther- mophilus isolates}

During storage, the yoghurts produced by the ten isolates could be separated into two groups with respect to their changing $\mathrm{pH}$ and TA (Fig. 2). Yoghurts produced by Group I isolates (IMAU20729, IMAU20738, IMAU20796, IMAU20713, IMAU20246, IMAU20765 and IMAU20764) continued to decrease in $\mathrm{pH}$ for $36-48 \mathrm{~h}$ in storage but with only minor changes in overall TA. In contrast, in yoghurts produced by Group 2 isolates (IMAU20728, IMAU20438 and IMAU20588) the $\mathrm{pH}$ decreased rapidly with large increases in TA. Purwandari and Vasiljevic (2009) reported storage time and variability amongst isolates significantly affected TA but that the storage temperature did not. They also observed that three $S$. thermophilus isolates had distinct acid-producing phases during storage. Post acidification is one of main causes of reductions in yoghurt sensory quality during storage (Han et al., 2014). Consequently, S. thermophilus isolates in Group I with greater TA stability and weak post-acidification during storage are

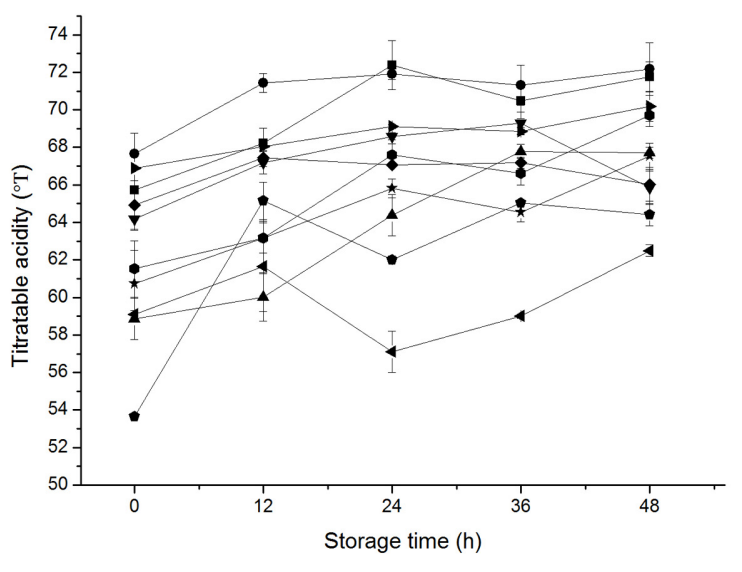


potentially more suitable for yoghurt production than the Group 2 isolates. There were no dramatic differences in the viable counts of $S$. thermophilus during storage (Fig. 2). Generally, slight decreases in the number of viable bacteria were observed as storage time increased.

Changes in lactic acid and formic acid concentration during storage of fermented milk produced by ten $S$. thermophiles

Generally, changes in lactic acid and formic acid concentration, was highly dependent on isolate (Fig. 3). Lactic acid is the main flavouring agent in yoghurt, contributing to its sour, refreshing taste. During storage, the concentration of lactic acid can change by varying degrees. In our study, the acidification ability of $S$. thermophilus was closely related to the final concentration of lactic acid. Formic acid is also an important metabolite of lactic acid fermentation and its production was isolate-dependent. Many researchers reported that $S$. thermophilus and L. bulgaricus had a good symbiotic role. With the growth of $S$. thermophius, the urease in S. thermophilus decomposes urea to produce $\mathrm{CO}_{2}$, and combining with the formic acid produced during growth to provide the conditions for the growth of L. bulgaricus. (Yu et al., 2014) During storage, yoghurt produced by isolate IMAU20246 had the highest concentration of both lactic acid and formic acid.

Overall there were some significant correlations between the acid-related compounds and other parameters (Table 3). In yoghurts produced by $S$. thermophilus isolates IMAU20764, IMAU20729 and IMAU20738 lactic acid concentration was significantly positively correlated
Table 3. Correlation analysis between different fermentation characteristics $(\mathbf{n}=\mathbf{5})$

\begin{tabular}{cccc}
\hline \hline Strains & Correlation & $p$ value & r value \\
\hline IMAU20246 & P vs F & 0.014 & 0.948 \\
IMAU20764 & TA vs L & 0.003 & 0.983 \\
& V vs L & 0.019 & 0.976 \\
IMAU20729 & V vs L & 0.019 & 0.937 \\
IMAU20738 & V vs L & 0.037 & 0.952 \\
\hline
\end{tabular}

TA, titratable acidity; P, pH; V, viable counts; F, formic acid; L, lactic acid.

with viable counts $(r=0.976, p=0.019),(r=0.937, p=0.019)$, $(r=0.952, p=0.037)$, respectively. It seems that the increase in viable counts also leads to greater production of lactic acid. For isolate IMAU20764, TA was significantly positively correlated with lactic acid concentration $(r=0.983$, $\mathrm{p}=0.003$ ). These relationships suggest that lactic acid is the main constituent of the overall acid content. For $S$. thermophilus isolate IMAU20246, there was a significant positive correlation between $\mathrm{pH}$ and formic acid concentration.

\section{Conclusions}

Here we describe the diversity of coccoidal bacterial species from traditionally fermented dairy products in Mongolia. Six species of coccoidal LAB were recorded, of which the predominant species was $S$. thermophilus. The acidification properties of ten selected S. thermophilus isolates were analyzed during fermention of milk and subsequent storage of the yoghurt produced. The production of organic acids varied considerably amongst the iso-
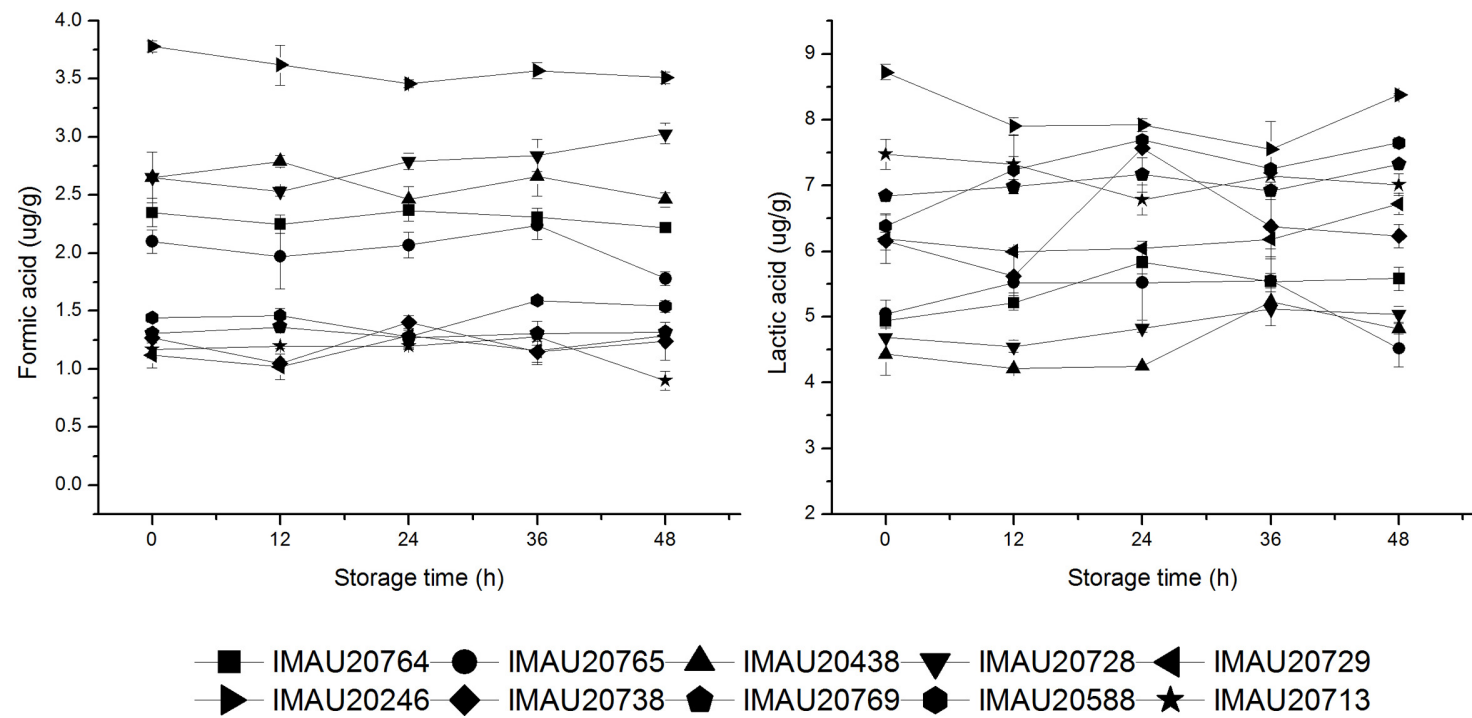

IMAU20438

Fig. 3. Effect of storage time on the content of lactic acid and formic acid in yoghurt produced using ten S. thermophilus isolates. 
lates and there were significant differences in the $\mathrm{pH}, \mathrm{TA}$ and viable counts of bacteria in the yoghurt produced by the ten isolates evaluated. Lactic acid was the major acidproduced component and formic acid was less predominant. These results provide the baseline data for selecting a good starter culture for traditional fermented dairy products. Some of the naturally occurring isolates we found have great potential as starter cultures for industrial production of traditional dairy products.

\section{Acknowledgements}

This research was supported by: China Agriculture Research System (Grant No. CARS-37), Natural Science Foundation in Inner Mongolia of China (Grant No. 2013 MS1206), and Specialized Research Fund for the Doctoral Program of Higher Education (Grant No. 20121515 130001).

\section{References}

1. Ali, A., Noh, N. M., and Mustafa, M. A. (2015) Antimicrobial activity of chitosan enriched with lemongrass oil against anthracnose of bell pepper. Food Packaging and Shelf Life 3, 56-61.

2. Badis, A., Guetarni, D., Moussa Boudjema, B., Henni, D. E., and Kihal, M. (2004) Identification and technological properties of lactic acid bacteria isolated from raw goat milk of four Algerian races. Food Microbiol. 21, 579-588.

3. Bruno, F. A., Lankaputhra, W. E. V., and Shah, N. P. (2002) Growth, viability and activity of Bifidobacterium spp. in skim milk containing prebiotics. J. Food Sci. 67, 2740-2744.

4. Castellano, P., González, C., Carduza, F., and Vignolo, G. (2010) Protective action of Lactobacillus curvatus CRL705 on vacuum-packaged raw beef. Effect on sensory and structural characteristics. Meat Sci. 85, 394-401.

5. Chammas, G. I., Saliba, R., Corrieu, G., and Béal, C. (2006) Characterisation of lactic acid bacteria isolated from fermented milk "laban". J. Int. Food Microbiol. 110, 52-61.

6. Chao, S. H., Wu, R. J., Watanabe, K., and Tsai, Y. C. (2009) Diversity of lactic acid bacteria in suan-tsai and fu-tsai, traditional fermented mustard products of Taiwan. Int. J. Food Microbiol. 135, 203-210.

7. Chaves, A. C. S. D., Fernandez, M., Lerayer, A. L. S., Mierau, I., and Hugenholtz, J. et al. (2002) Metabolic engineering of acetaldehyde production by Streptococcus thermophilus. Appl. Environ. Microbiol. 68, 5656-5662.

8. Chen, X., Du, X., Wang, W., Zhang, J., and Zhang, H. et al. (2010) Isolation and identification of cultivable lactic acid bacteria in traditional fermented milk of Tibet in China. Int. J. Dairy Technol.63, 437-444.

9. Coeuret, V., Dubernet, S., Bernardeau, M., Gueguen, M., and Vernoux, J. P. (2003). Isolation, characterisation and identifi- cation of lactobacilli focusing mainly on cheeses and other dairy products. Le Lait 83, 269-306.

10. Donkor, O. N., Henriksson, A., Vasiljevic, and T., and Shah, N. P. (2006) Effect of acidification on the activity of probiotics in yoghurt during cold storage. Int. Dairy J. 16, 1181-1189.

11. Erkus, O., Okuklu, B., Yenidunya, A. F., and Harsa, S. (2014) High genetic and phenotypic variability of Streptococcus thermophilus strains isolated from artisanal Yuruk yoghurts. $J$. LWT-Food Sci. Technol. 58, 348-354.

12. Güler Akin, M. B. and Akn, M. S. (2007) Effects of cysteine and different incubation temperatures on the microflora, chemical composition and sensory characteristics of bio-yogurt made from goat's milk. Food Chem. 100, 788-793.

13. Han, X., Zhang, L., Yu, P., Yi, H., and Zhang, Y. (2014) Potential of LAB starter culture isolated from Chinese traditional fermented foods for yoghurt production. Int. Dairy J. 34, 247-251.

14. Letort, C. and Juillard, V. (2001) Development of a minimal chemically - defined medium for the exponential growth of Streptococcus thermophilus. J. Appl. Mcrobiol. 91, 1023-1029.

15. Li, W., Mutuvulla, M., Chen, X., Jiang, M., and Dong, M. (2012) Isolation and identification of high viscosity-producing lactic acid bacteria from a traditional fermented milk in Xinjiang and its role in fermentation process. Eur. Food Res. Technol. 235, 497-505.

16. Liu, S. N., Han, Y., and Zhou, Z. J. (2011) Lactic acid bacteria in traditional fermented Chinese foods. Food Res. Int. 44, 643-651.

17. Lu, Z. H., Peng, H. H., Cao, W., Tatsumi, E., and Li, L. T. (2008) Isolation, characterization and identification of lactic acid bacteria and yeasts from sour Mifen, a traditional fermented rice noodle from China. J. Appl. Microbiol. 105, 893903.

18. Mohd Adnan, A. F. and Tan, I. K. (2007) Isolation of lactic acid bacteria from Malaysian foods and assessment of the isolates for industrial potential. Meat Sci. 98, 1380-1385.

19. Purwandari, U. and Vasiljevic, T. (2009) Rheological properties of fermented milk produced by a single exopolysaccharide producing Streptococcus thermophilus strain in the presence of added calcium and sucrose. Int. J. Dairy Technol. 62, 411-421.

20. Soomro, A. H. and Masud, T. (2008) Selection of yoghurt starter culture from indigenous isolates of Streptococcus thermophilus and Lactobacillus delbrueckii subsp. bulgaricus on the basis of technological properties. Ann. Microbiol. 58, 6771.

21. Tabasco, R., Fernández de Palencia, P., Fontecha, J., Peláez, C., and Requena, T. (2014) Competition mechanisms of lactic acid bacteria and bifidobacteria: fermentative metabolism and colonization. J. LWT-Food Sci. Technol. 55, 680-684.

22. Tharmaraj, N. and Shah, N. P. (2003) Selective Enumeration of Lactobacillus delbrueckii ssp. bulgaricus, Streptococcus thermophilus, Lactobacillus acidophilus, Bifidobacteria, Lactobacillus casei, Lactobacillus rhamnosus, and Propionibacteria. J. Dairy Sci. 86, 2288-2296.

23. Vélez, M. P., Hermans, K., Verhoeven, T. L. A., Lebeer, S. E., 
and De Keersmaecker, S. C. J. et al. (2007) Identification and characterization of starter lactic acid bacteria and probiotics from Columbian dairy products. J. Appl. Microbiol. 103, 666-674.

24. Wang, J. G., Chen, X., Liu, W. J., Yang, M., Airidengcaicike, and Zhang, H. P. (2008) Identification of Lactobacillus from koumiss by conventional and molecular methods. Eur. Food Res. Technol. 227, 1555-1561.

25. Yu, J. (2014) Multilocus Sequence Typing of Streptococcus thermophilus from Traditional Fermented Dairy Products in China, Russia and Mongolia. Ph.D. thesis, IMAU, China.

26. Yu, J., Gao, W., Qing, M., Sun, Z., and Zhang, H. et al. (2012)
Identification and characterization of lactic acid bacteria isolated from traditional pickles in Sichuan, China. J. Gen. Appl. Microbiol. 58, 163-172.

27. Yu, J., Wang, W. H., Menghe, B. L. G., Jiri, M. T., and Zhang, H. P. et al. (2011) Diversity of lactic acid bacteria associated with traditional fermented dairy products in Mongolia. J. Dairy Sci. 94, 3229-3241.

28. Zha, M., Yu, J., Zhang, Y., Wang, H., Bai, N., Qin, Y., and Bilige, M. et al. (2015). Study on Streptococcus thermophilus isolated from Qula and associated characteristic of acetaldehyde and diacetyl in their fermented milk. J. Gen. Appl. Microbiol. 61, 50-56. 